\title{
Epidemiology of Mortality in Polyvalent Intensive Care Unit at University Hospital of Brazzaville
}

\author{
Marie Elombila1,2*, Christ Mayick Mpoy Emy Monkessa ${ }^{2 *}$, Gilbert Fabrice Otiobanda ${ }^{1,2}$, \\ Hugues Brieux Ekouele Mbaki ${ }^{1,3}$, Gilles Niengo Outsouta ${ }^{2}$, Marina Aurole Nde Ngala ${ }^{2}$ \\ ${ }^{1}$ Department of Anaesthesia and Intensive Care, Faculty of Heath Sciences, Marien Ngouabi University, Brazzaville, \\ Republic of Congo \\ ${ }^{2}$ Polyvalent Intensive Care Unit, University Hospital of Brazzaville, Brazzaville, Republic of Congo \\ ${ }^{3}$ Department of Surgery, University Hospital of Brazzaville, Brazzaville, Republic of Congo \\ Email: *elombila@gmail.com, *christerad@gmail.com
}

How to cite this paper: Elombila, M., Monkessa, C.M.M.E., Otiobanda, G.F., Mbaki, H.B.E., Outsouta, G.N. and Ngala, M.A.N. (2018) Epidemiology of Mortality in Polyvalent Intensive Care Unit at University Hospital of Brazzaville. Open Journal of Emergency Medicine, 6, 112-121.

https://doi.org/10.4236/ojem.2018.64013

Received: November 19, 2018 Accepted: December 17, 2018

Published: December 20, 2018

Copyright $(9) 2018$ by authors and Scientific Research Publishing Inc. This work is licensed under the Creative Commons Attribution International License (CC BY 4.0).

http://creativecommons.org/licenses/by/4.0/

\begin{abstract}
Aim: To describe the epidemiological aspects of the patients who died in polyvalent intensive care unit at University Hospital of Brazzaville. Materials and Methods: This was a retrospective, cross-sectional study carried out in intensive care unit of University Hospital of Brazzaville, during period from January 2013 to December 2014. All patients who died at the unit regardless of age or sex were included. The parameters studied were age, sex, origin, reason for admission, causes of death, time of death, and length of hospitalization. Data were treated in Excel 2010 and Epi info 2007. Results: During the study period, 419 deaths out of 1121 admissions were recorded, representing a mortality rate of $37.4 \%$. The average age was $46.2 \pm 19.7$ years with extremes ranging from 14 months to 90 years. The sex ratio was 0.9 . Most of the deceased patients came from medical emergencies in $37.6 \%$ of the cases. Infectious $(17.9 \%)$ and neurological $(17.4 \%)$ pathologies were the most likely to cause death followed by cardiovascular pathologies (12.2\%). Causes of death were dominated by severe sepsis and septic shock with $93.4 \%$ of infectious pathologies and stroke in $80.8 \%$ of neurological pathologies. In $42.3 \%$ of cases, the death occurred in the 8:00 p.m. to 6:00 a.m. time period. The average length of hospitalization for the deceased patients was $1.4 \pm 0.5$ days. All parameters studied significantly associated with mortality $(\mathrm{p}<0.05)$. Conclusion: The mortality rate of patients admitted to the polyvalent intensive care unit at University Hospital of Brazzaville was high at 37.4\%. Most of these patients were aged 40 years and older, male, with infectious and/or neurological pathologies. All deaths occurred within 48 hours of admission.
\end{abstract}




\section{Keywords}

Epidemiology, Mortality, Intensive Care Unit, Brazzaville

\section{Introduction}

Medical advances in recent years have made it possible to keep patients who would once have been terminally ill alive for weeks or even months. In a hospital's care system, emergency and resuscitation services are at the forefront of action, thus constituting the sites of many deaths [1] [2]. Admission in intensive care unit usually occurs in a context of failure of vital functions thus exposing at the death. Death is a major event whose evaluation and analysis is necessary to improve the quality of patient care in a hospital in general, and in intensive care in particular [3] [4].

In the United States, the average intensive care unit mortality rate ranges from $8 \%$ to $19 \%$, an estimated 500,000 deaths per year. In France, the average mortality rate in intensive care units is estimated at $15 \%$ with hospital mortality ranging from $20 \%$ to $30 \%$ according to studies [5] [6]. In Africa, resuscitation mortality has been the subject of several studies [2] [4] [7] [8] [9] [10]. In Burkina Faso, in the multipurpose intensive care unit of the Ouagadougou Hospital Center, the rate of mortality achieved $63 \%$ of cases with a clear prevalence of medical pathologies [7].

In Congo, in the polyvalent intensive care unit of the University Hospital of Brazzaville, various studies on pregnancy complications and patients aged 60 and over have all found a mortality rate between $18.9 \%$ and $66.0 \%$ [8] [9] [10]. However, no studies have been carried out on the causes and characteristics of mortality.

The aim of our study is to describe the epidemiological aspects of the patients who died in polyvalent intensive care at University Hospital of Brazzaville.

\section{Materials and Methods}

This was a cross-sectional and retrospective study carried out in polyvalent intensive care unit of the University Hospital of Brazzaville over a two-year period from January 1, 2013 to December 31, 2014. The general study population consisted of all patients admitted to the department. We included in our study all patients who died in the unit regardless of age or gender. Patients with missing data or who died on arrival were excluded from our study. The data collection was based on the admissions register. These data were then recorded on a survey sheet developed for this study. The parameters studied were age, sex, origin, reason for admission, causes of death, time of death, length of hospitalization.

Data analysis was performed using Excel 2010 and Epi info 2007 software. The quantitative variables were expressed as an average \pm standard deviation and the qualitative variables were expressed as numbers and percentages. The compari- 
son of proportions and percentages was made with the Chi-square test. The $\mathrm{p}<$ 0.05 was considered to be statistically significant.

\section{Results}

During the study period, 419 deaths out of 1121 admissions were recorded, for a mortality rate of $37.4 \%$. The average age of deceased patients was $46.2 \pm 19.7$ years with extremes ranging from 14 months to 90 years. The $20-39$ and $40-59$ age groups were the most represented with $33.7 \%$ and $29.1 \%$ of cases respectively. In $46.5 \%$ of the patients were male and $53.5 \%$ female, for a sex ratio of 0.9 . Deceased patients were from medical emergencies in $37.6 \%$ of cases and from other specialized services in $26.2 \%$ of cases. The latter were dominated by cardiology, neurology and gastroenterology. Infectious and neurological pathologies were responsible for death in $17.9 \%$ and $17.4 \%$ of cases respectively followed by cardiovascular pathologies in $12.2 \%$ of cases. Table 1 indicates the sociodemographic and clinical characteristics of deceased patients in our study. In our study, causes of death were represented by severe sepsis and septic shock (respectively $74.7 \%$ and $18.7 \%$ of infectious pathologies), by stroke $(80.8 \%$ of neurological pathologies), by decompensations of heart failure and cardiogenic shock (respectively $54.9 \%$ and $21.6 \%$ of cardiovascular pathologies) and by the acute complications of diabetes (78.4\% of metabolic and renal diseases). In $42.3 \%$ of cases, death occurred in the 8:00 p.m. to 6:59 a.m. time period (Table 2 ). The average length of stay for deceased patients was $1.4 \pm 0.5$ days.

For all variables analyzed, we found a statistically significant difference ( $\mathrm{p}<$ 0.05). Table 3 presents the univariate analysis of the mortality of patients in intensive care.

\section{Discussion}

In our study, the mortality rate was $37.4 \%$. This rate is similar to those found by Rasamoelina et al. as well as Tchaou et al. who reported an overall mortality of $37.5 \%$ and $37.7 \%$ in their studies respectively on the mortality of digestive emergencies in Madagascar and the obstetric morbidity in intensive care in Benin [11] [12]. It is close to that of Nabiliou et al. who noted an overall mortality of $34.1 \%$ in their study of patients admitted in polyvalent intensive care unit of University hospital of So [13]. In our study the mortality rate is high, this result is higher than those of some authors, who have noted a mortality rate between $32.0 \%$ and $33.0 \%$ [14] [15] [16]. Other authors found a much lower rate ranging from 7.3\% to 28.3\% [1] [2] [4] [17] [18]. Colpan et al., Konan et al. and Bonkoungou et al. found a much higher mortality rate of $46.7 \%$ and $52.2 \%$ of cases in their respective studies [19] [20] [21]. This difference could be explained by the type of population studied, the size of the sample, the existence of armed conflict or not in the study, the lack of a technical platform for resuscitation services in developing countries in general, the delay in treatment, the unavailability of emergency kits and the absence of health insurance. Also, Intensive care 
Table 1. Sociodemographic and clinical characteristics of deceased patients.

\begin{tabular}{|c|c|}
\hline & Effective (percentage) \\
\hline \multicolumn{2}{|l|}{ Age group } \\
\hline$<20$ years & $36(8.6 \%)$ \\
\hline $20-39$ years & $141(33.7 \%)$ \\
\hline $40-59$ years & $122(29.1 \%)$ \\
\hline$\geq 60$ years & $120(28.6 \%)$ \\
\hline \multicolumn{2}{|l|}{ Gender } \\
\hline Male & $195(46.5 \%)$ \\
\hline Female & $224(53.5 \%)$ \\
\hline \multicolumn{2}{|l|}{ Origin } \\
\hline Medical emergencies & $149(35.6 \%)$ \\
\hline Others specialized services of $U H B^{*}$ & $110(26.2 \%)$ \\
\hline Operating room & $89(21.2 \%)$ \\
\hline Gynecologic obstetrical emergencies & $41(9.8 \%)$ \\
\hline Surgical emergencies & $20(4.8 \%)$ \\
\hline External & $10(2.4 \%)$ \\
\hline \multicolumn{2}{|l|}{ *Others specialized services of UHB } \\
\hline Cardiology & $16(14.5 \%)$ \\
\hline Neurology & $13(11.8 \%)$ \\
\hline Gastroenterology & $12(10.9 \%)$ \\
\hline Pneumology & $11(10.0 \%)$ \\
\hline Rhumatology-Dermatology & $10(9.1 \%)$ \\
\hline Hematology & $7(6.4 \%)$ \\
\hline Polyvalent surgery & $7(6.4 \%)$ \\
\hline Metabolic and renal diseases & $6(5.5 \%)$ \\
\hline Pediatric intensive care & $5(4.5 \%)$ \\
\hline Infectious diseases & $5(4.5 \%)$ \\
\hline Digestive surgery & $5(4.5 \%)$ \\
\hline Urology & $3(2.7 \%)$ \\
\hline Traumatology-Orthopedics & $3(2.7 \%)$ \\
\hline Nephrology & $2(1.8 \%)$ \\
\hline Stomatology-ORL & $2(1.8 \%)$ \\
\hline Pediatrics for older children & $1(0.9 \%)$ \\
\hline Pediatric surgery & $1(0.9 \%)$ \\
\hline External consultation & $1(0.9 \%)$ \\
\hline \multicolumn{2}{|l|}{ Reason for admission } \\
\hline Infectious diseases & $75(17.9 \%)$ \\
\hline Neurological pathologies & $73(17.4 \%)$ \\
\hline Cardiovascular diseases & $51(12.2 \%)$ \\
\hline Gynecologic-obstetrical pathologies & $50(12.0 \%)$ \\
\hline Post-operative care & $41(9.8 \%)$ \\
\hline Metabolic and renal diseases & $37(8.8 \%)$ \\
\hline Respiratory diseases & $33(7.9 \%)$ \\
\hline Traumatological pathologies & $26(6.2 \%)$ \\
\hline Digestive pathologies & $9(2.1 \%)$ \\
\hline Others & $24(5.7 \%)$ \\
\hline
\end{tabular}

UHB: University hospital of Brazzaville; ORL: Oto-Rhino-Laryngology. 
Table 2. Distribution of deceased patients by time of death.

\begin{tabular}{cc}
\hline & Effective (percentage) \\
\hline 0:00 to 6:59 a.m & $119(28.4 \%)$ \\
2:00 to 7:59 p.m & $99(23.6 \%)$ \\
7:00 a.m to 1:59 p.m & $78(18.6 \%)$ \\
Unknow & $65(15.5 \%)$ \\
8:00 to 11:59 p.m & $58(13.9 \%)$ \\
Total & $419(100.0 \%)$ \\
\hline
\end{tabular}

Table 3. Analysis between mortality and others parameters (age, gender, origin and reason for admission).

\begin{tabular}{|c|c|c|c|c|}
\hline & $\mathrm{N}$ & $\mathrm{n}$ & $\%$ death & $p$ value \\
\hline \multicolumn{5}{|l|}{ Age groups (years) } \\
\hline$<20$ & 147 & 36 & $24.5 \%$ & \\
\hline $20-39$ & 475 & 141 & $29.7 \%$ & $<0.01$ \\
\hline $40-59$ & 281 & 122 & $43.3 \%$ & \\
\hline$\geq 60$ & 218 & 120 & $55.0 \%$ & \\
\hline \multicolumn{5}{|l|}{ Gender } \\
\hline Male & 418 & 195 & $46.7 \%$ & 0.000001 \\
\hline Female & 703 & 224 & $31.9 \%$ & \\
\hline \multicolumn{5}{|l|}{ Origin } \\
\hline Others services of $U H B$ & 172 & 110 & $64.0 \%$ & \\
\hline Medical emergencies & 305 & 149 & $48.9 \%$ & \\
\hline Surgical emergencies & 53 & 20 & $37.7 \%$ & 0.00067 \\
\hline Gynecologic-obstetrical emergencies & 147 & 41 & $27.9 \%$ & \\
\hline Operating room & 391 & 89 & $22.8 \%$ & \\
\hline External & 53 & 10 & $18.9 \%$ & \\
\hline \multicolumn{5}{|l|}{ Reason for admission } \\
\hline Infectious diseases & 102 & 75 & $73.5 \%$ & \\
\hline Neurological pathologies & 128 & 73 & $57.0 \%$ & \\
\hline Metabolic and renal diseases & 77 & 37 & $48.1 \%$ & \\
\hline Cardiovascular diseases & 107 & 51 & $47.7 \%$ & \\
\hline Traumatological pathologies & 78 & 26 & $33.3 \%$ & $<0.01$ \\
\hline Digestive pathologies & 27 & 9 & $33.3 \%$ & \\
\hline Respiratory pathologies & 100 & 33 & $33.0 \%$ & \\
\hline Post operative care & 176 & 41 & $23.3 \%$ & \\
\hline Gynecologic-obstetrical pathologies & 299 & 50 & $16.7 \%$ & \\
\hline Others* & 27 & 24 & $88.9 \%$ & \\
\hline Total & 1121 & 419 & $37.4 \%$ & \\
\hline
\end{tabular}

$\mathrm{N}$ : Total number of patients admitted during the study period; $\mathrm{n}$ : Number of patients who died during the study period; \%: Percentage; *: Tumor, hematological, neurosurgical pathologies and system diseases.

unit is the service with the highest mortality rate compared to others in a health facility. 
The average age of the deceased patients was $46.2 \pm 19.7$ years (extremes from 14 months to 90 years). The age groups 20 to 39 years and 40 to 59 years were the most represented by death with $33.7 \%$ and $29.1 \%$ of cases respectively. Our average age is similar to that of Zoumenou et al. ( $46 \pm 21$ years) and Koukous et al. (47.7 \pm 19.7 years), in their study of mortality in emergency and resuscitation departments [4] [22]. The prevalence of the 20 - 40 age group was also reported by Metogo et al:; Najall et al. noted a prevalence of the 25 - 45 age group [2] [23].

In our study, the female sex was predominant. Some authors had noted a male predominance in their study [14] [24]. The large number of women could explain this difference during the study period, which shows the importance of gynecological and obstetrical activity in our department.

In terms of origin, medical emergencies and other hospital services accounted for $35.6 \%$ and $26.3 \%$ of all deaths respectively. These results may be justified by the late consultation of patients, mainly related to socio-cultural beliefs and financial difficulties of the majority of families, a long delay between consultation and initial care, as well as a late transfer to an intensive care unit. Sometimes this initial care may be inadequate causing a delay in management.

In our study, infectious and neurological pathologies were responsible for deaths with $73.5 \%$ and $57.0 \%$ of the respective cases. These results are superimposed on those of Tchaou et al. who found infectious diseases to be the leading cause of death in their study [11]. Koukous et al. noted septic shock and neurological pathologies as the main causes of death in their study on mortality factors in intensive care in Morocco [4]. This observation could be explained by the delay in the treatment of infections due, especially in our region, to the lack of diagnostic resources, particularly biology, including culture bacteriological, the resistance of germs to common antibiotics and the lack of financial resources for the purchase of antibiotics by families. However, Diouf et al. reported that mortality was higher among patients admitted for cardiovascular diseases $(75.0 \%$ of deaths) followed by neurological disorders (68.3\% of deaths); infectious diseases and metabolic and renal disorders accounted for $46.1 \%$ and $46.6 \%$ of deaths respectively [15].

Causes of death were represented by severe sepsis and septic shock $(74.7 \%$ and $18.7 \%$ of infectious pathologies respectively), by stroke ( $80.8 \%$ of neurological pathologies), by decompensations of heart failure and cardiogenic shock (54.9\% and $21.6 \%$ of cardiovascular pathologies respectively) and by the acute complications of diabetes (78.4\% of metabolic and renal diseases). Some authors close to those observe these findings. Metogo et al. found stroke and septic shock as medical aetiologies of death in intensive care in Cameroon [2]. Bonkoungou et al., in their study on mortality in intensive care in Burkina Faso, noted that the most common reasons for admission in deceased patients were stroke (22.9\%), trauma brain injury (22.1\%) and severe infection (18.3\%) [21]. For their part, Zoumenou et al. reported that the most causes of death in the emergency department were stroke (27.8\%), severe trauma (15.5\%) and acute complications of diabetes 
(7.2\%), chronic renal failure (6.6\%), and AIDS opportunists (6.2\%) [22].

The mortality was highest in the $60+$ age group ( $55.0 \%$ of cases) followed by 40 - 59 years (43.4\% of cases). A statistically significant difference was observed between age and mortality. This can be justified by a low life expectancy of around 55 years in our country, the development of cardiovascular risk with the ageing of the population and the increase in cardiovascular risk factors with age.The death rate was higher among male patients with $46.7 \%$ versus $31.9 \%$ for female patients.

In our series, mortality was higher among patients from other specialized hospital services ( $64.0 \%$ of cases) and medical emergencies (48.9\%). Similar data have been reported by Diouf et al. [15]. Statistical analysis between the origin and mortality of intensive care patients showed a significant difference $(\mathrm{p}<$ 0.05). This difference could be explained by the absence of intensive care units in the specialized hospitalization and emergency services of the University Hospital of Brazzaville, thus partly justifying the delay in the management of vital failures. Also, emergency departments are, according to the literature, the largest providers of intensive care admissions [15] [25].

In our study, $42.3 \%$ of patients died in the $8: 00$ p.m. to $6: 59$ a.m. time period. This result is superimposable to that reported by Egbohou et al. who noted in their study that $51.9 \%$ of deaths occurred during the 17 -hours to 7 -hours period [14]. These trends can be justified by the decreased vigilance of nurses' team in night duty responsible for the lack of patient monitoring during this period and by also the lack of human resources in our unit. Indeed, each nurses team in night duty consisted of three nurses for a total of 11 beds, i.e. a ratio of 3.6 patients/nurse or two nurses with a technical health worker, i.e. a ratio of 5.5 patients/nurse.

The average length of stay for deceased patients was $1.4 \pm 0.5$ days. Najall et al. noted that patients died within 24 hours of admission to intensive care in $46.0 \%$ of cases [23]. Egbohou et al. reported that deaths occurred in $42.2 \%$ within 48 hours after admission to intensive care [14].

For a better interpretation of our results, certain limitations in our study must be taken into account. Indeed, her retrospective nature did not allow us to codify patient information, to know the clinical severity of patients at admission that could justify their death within 48 hours. Also, the not used of medical records that proved incomplete and unusable, the failure of to not record hours and even reasons for death of patients on the records, also constituted limitations in our study.

The results reported in our study allowed to propose some more strategic ways for reducing mortality rate in our department. There are the reduction of patients'admission period for promoting support for vital failure, the creation of the intensive care units or room in other hospitalization specialized services in order to facilitate the initiation of more specific treatments such as oxygen therapy and monitoring of patients, the availability of kit or emergengy medications 
that can allow to start the care during the first hours, the reduction of cardiovascular risk factors and management chronic pathologies such as diabetes and high blood pressure, the improvement of technical platform and the continuous training of nursing staff.

\section{Conclusion}

The mortality rate of patients admitted to the polyvalent intensive care unit at University Hospital of Brazzaville is high at 37.4\%. These were mainly adult male patients aged 40 and over from other specialized hospital and emergency departments with infectious and/or neurological conditions. All deaths occurred within 48 hours of admission. The reduction of this mortality rate will require, among other things, the implementation of morbi-mortality review meetings, the improvement of the technical platform, the availability of emergency products, and an increase in the number of medical staff.

\section{Conflicts of Interest}

The authors declare no conflicts of interest regarding the publication of this paper.

\section{References}

[1] Daddy, H., Adehossi, E., Gagara, M., et al. (2014) Epidemiological Aspects of Patients Admitted in the Intensive Care Unit of Niamey National Hospital. Revue Africaine d' Anesthésiologie et de Médecine d Urgence, 19, 42-46.

[2] Metogo Mbengono, J.A., Bengono, B.R., Nkodo, M.J., et al. (2015) Death's Aetiologies in Emergency and Intensive Care Services of Two Hospitals of the City of Yaounde. Health Sciences And Diseases, 16, 1-5.

[3] Boles, J.M. and Jousset, D. (2011) Pathways of Vulnerability in Adult Intensive Care Unit: Clinical Dimensions and Philosophical Issues. Revue Laennec, 59, 42-54. https://doi.org/10.3917/lae.112.0042

[4] Koukous, A. (2010) Mortality Factors in Intensive Care Unit: Prospective Study. Ph.D. Thesis, Sidi Mohammed Ben Abdellah University, Fès.

[5] Sidiqui, S. (2015) Mortality Profile across Our Intensive Care Units: A 5-Year Database Report from a Singapore Restructured Hospital. Indian Journal of Critical Care Medicine, 19, 726-727. https://doi.org/10.4103/0972-5229.171401

[6] Resche-Rigon, M., Azoulay, E. and Chevret, S. (2006) Evaluating Mortality in Intensive Care Units: Contribution of Competing Risks Analyses. Critical Care Medicine, $10,1-6$.

[7] Ouedrago, N., Niakera, A., Somné, A., et al. (2002) Intensive Care in Africa: A Report of the First Two Years of Activity of the Intensive Care Unit of Ouagadougou National Hospital (Burkina Faso). Sante (Montrouge, France), 4, 375-382.

[8] Otiobanda, G.F., Mahoungou Guimbi, K.C., Ellenga-Mbola, B.F., et al. (2012) Morbidity and Mortality of Obstetric Patients Admitted to an Intensive Care Unit. Revue Africaine d' Anesthésiologie et de Médecine d' Urgence,17, 39-44.

[9] Otiobanda, G.F., Itoua, C., Ossou-Nguiet, P.M., et al. (2013) Epidemiological, Clinical Aspects and Outcomes of Eclampsia in Intensive Care Unit at Univerity Hospital of Brazzaville. Revue Cames Santé, 1, 46-50. 
[10] Mahoungou Guimbi, K.C., Ellenga-Mbolla, B.F., Otiobanda, G.F., et al. (2011) Mortality and Admission Causes in Intensive Care Unit in Elderly Patients at Brazzaville. Annales Africaines de Médecine, 5, 957-963.

[11] Rasamoelina, N., Rajaobelison, T., Ralahy, M.F., et al. (2010) Risk Factors of Mortality by Urgent Digestive Affections in the Intensive Care Unit of the Teaching Hospital of Fianarantsoa Madagascar. Revue d'Anesthésie-Réanimation et de Médecine d'Urgence, 2, 10-11.

[12] Tchaou, B.A., Tshabu-Aguèmon, C., Hounkponou, F.M., et al. (2013) Serious Obstetric Morbidity in Intensive Care Unit in the University Hospital of Parakou (Benin) about Sixty Nine Cases. Revue Africaine d Anesthésiologie et de Médecine d Urgence, 18.

[13] Nabiliou, M., Tomta, K., Mouzou, T., et al. (2014) Epidemiological, Diagnostic, Therapeutic and Evolutionary Aspects of Admitted Patients to Intensive Care Unit of Hospital Center Sylvio Olympio. Revue Africaine d Anesthésiologie et de Médecine d Urgence, 19, 57.

[14] Egbohou, P., Mouzou, T., Tomta, K., Sama, H. and Assenouwe, S. (2014) Epidemiology of Mortality at Intensive Care Unit of Hospital Center Sylvio Olympio of Lome. Revue Africaine d'Anesthésiologie et de Médecine d Urgence, 19, 32.

[15] Diouf, E., Leye, P.A., Bah, M.D., et al. (2014) Admission Rules of Patients in Intensive Care Unit in Africa and Consequences on the Evolution. Revue Africaine d Anesthésiologie et de Médecine d Urgence, 19, 79-84.

[16] Benois, A., Raynaud, L., Coton, T., et al. (2009) Morbidity and Mortality after Intensive Care Management of Hemorrhagic Stroke in Djibouti. Médecine Tropicale, 69, 41-44.

[17] Capuzzo, M., Volta, C.A., Tassinati, T., et al. (2014) Hospital Mortality of Adults Admitted to Intensive Care Units in Hospitals with and without Intermediate Care Units: A Multicentre European Cohort Study. Critical Care, 18, 551. https://doi.org/10.1186/s13054-014-0551-8

[18] Lipshutz, A.K.M., Feiner, J.R., Grimes, B. and Gropper, M.A. (2016) Predicting Mortality in the Intensive Care Unit: A Comparison of the University Health Consortium Expected Probability of Mortality and the Mortality Prediction Model III. Journal of Intensive Care, 4, 35. https://doi.org/10.1186/s40560-016-0158-Z

[19] Colpan, A., Akinci, E., Erbay, A., Balaban, N. and Bodur, H. (2005) Evaluation of Risk Factors for Mortality in Intensive Care Units: A Prospective Study from a Referral Hospital in Turkey. American Journal of Infection Control, 33, 42-47. https://doi.org/10.1016/j.ajic.2004.09.005

[20] Konan, K.J., Babo, C.J., Ayé, Y.D., et al. (2013) Epidemiological Aspects of Admissions in the Intensive Care Unit of Yopougon University Hospital during the Post-Election Armed Conflict in Côte d'ivoire. Revue Africaine d'Anesthésiologie et de Médecine d'Urgence, 18, 33-38.

[21] Bonkoungou, P., Traoré, Bako, Y.P.I., Sanou, J. and Ouédraogo, N. (2014) Mortality in Intensive Care Unit at University Hospital Yalgado Ouédraogo of Ouagadougou, Burkina-Faso. Annales Françaises d Anesthésie et de Réanimation, 33, A310. https://doi.org/10.1016/j.annfar.2014.07.523

[22] Zoumenou, E., Lokossou, T.C., Assouto, P., Soton, F. and Chobli, M.K. (2014) Critical Analysis of Mortality in an Emergency Department in Subsaharan Africa: Epidemiology and Reduction Prospects. Annales Françaises d'Anesthésie et de Réanimation, 33, A343.

[23] Najall Pouth, C., Bita Fouda, A.A., Beyiha, G., et al. (2012) Prognosis Factors in 
Patients with Severe Trauma Admitted in Intensive Care at Laquintinie Hospital in Douala. Revue Africaine d' Anesthésiologie et de Médecine d' Urgence, 17.

[24] Belayachi, J., Dendane, T., Madani, N., et al. (2012) Factors Predicting Mortality in Elderly Patients Admitted to a Moroccan Medical Intensive Care Unit. Southern African Journal of Critical Care, 28, 22-27.

[25] Boffelli, S., Rossi, C., Aughileri, A., et al. (2006) Continuous Quality Improvement in Intensive Care Medicine. The GiViTI Margherita Project-Report 2005. Minerva Anestesiologica, 72, 419-432. 